\title{
A Facile and Green Synthetic Route for Preparation of Heterostructure $\mathrm{Fe}_{3} \mathrm{O}_{4} @ A u$ Nanocomposites
}

\author{
Liping Xie ${ }^{1, a}$, Wei Qian ${ }^{1, a}$, Sheng Yang ${ }^{2}$, Jianjun Sun ${ }^{1}$ and Tianxing Gong ${ }^{1}$. \\ ${ }^{1}$ Sino-Dutch Biomedical and Information Engineering School, Northeastern University, 110004, Shenyang, China \\ ${ }^{2}$ College of Life and Health Science, Northeastern University, 110004, Shenyang, China
}

\begin{abstract}
Magnetic nanoparticles offer many exciting opportunities in biology and biomedicine, such as magnetic resonance imaging, magnetic hyperthermia therapy, biomedical diagnosis. The synthesis of multifunctional magnetic nanocomposites that possess watersolubility, magnetic properties and optical stability by a green method at room temperature in aqueous phase is still an unmet need. Here, we developed a simple and green method for preparing $\mathrm{Fe}_{3} \mathrm{O}_{4} @ \mathrm{Au}$ integrated the super-paramagnetic and optical properties by seedmediated growth at mild condition in aqueous phase. The amphiphilic, non-ionic and nontoxic polymer poly(vinylpyrrolidone) (PVP) was used as a coupling agent for synthesis of $\mathrm{Fe}_{3} \mathrm{O}_{4} @ \mathrm{Au}$ nanocomposites, which avoided the direct connection of $\mathrm{Au}$ and $\mathrm{Fe}_{3} \mathrm{O}_{4}$, and improved the saturation magnetization values of $\mathrm{Fe}_{3} \mathrm{O}_{4} @ \mathrm{Au}$ to $40 \mathrm{emu} / \mathrm{g}$ at room temperature. We anticipate that the multifunctional $\mathrm{Fe}_{3} \mathrm{O}_{4} @ \mathrm{Au}$ nanocomposites with high magnetic and good optical properties will provide a platform for potential diagnostic and therapeutic biomedical applications.
\end{abstract}

\section{Introduction}

Magnetic iron oxide nanoparticles (MNPs) have attracted considerable interest due to its superparamagnetism, and offered many exciting opportunities in biology and biomedicine, including magnetic resonance imaging, magnetic hyperthermia therapy, biosensor, separation and purification of protein and cell [1-5]. Meanwhile, the gold NPs have been extensively used in biosensor, surface enhanced Raman spectroscopy, and therapy applications, due to its well-known catalytic activity, optical properties, chemical functionality, and biocompatibility [6-8]. Bifunctional nanomaterial integrates gold and iron oxides into a single nano-platform, and by combining the advantages of gold and iron oxides, it shows enhanced physical and chemical properties [9]. Au shell layers provide stability and easy functionalization to the nanocomposites in solution, and render the magnetic NPs with plasmonic properties.

There are a number of literatures about the synthesis of MNPs@Au nanocomposites. Various nanocomposites with high shape regularity and a narrow size distribution were prepared by the thermolysis of organometallic precursors in hot organic solutions $\left(180-190{ }^{\circ} \mathrm{C}\right)[10,11]$, or via thermally activated hetero-interparticle coalescence between gold and magnetic NPs under an

\footnotetext{
a Corresponding author: xielp@bmie.neu.edu.cn and weiq@bmie.neu.edu.cn
} 
encapsulating environment at temperature elevation $\left(140-160^{\circ} \mathrm{C}\right)$ [12]. All these methods involve hot organic solutions, resulting in the NPs capped with organic surfactants, which render them unsuitable for biomedical applications. Sun et al. synthesized the oleylamine and oleic acid capped $\mathrm{Fe}_{3} \mathrm{O}_{4} \mathrm{NPs}$ via thermal decomposition of iron(III) leate in a mixture of oleylamine and oleic acid, and then, they synthesized the $\mathrm{Fe}_{3} \mathrm{O}_{4} / \mathrm{Au}$ NPs in a chloroform solution in the presence of the $\mathrm{Fe}_{3} \mathrm{O}_{4}$ NPs. Core/shell $\mathrm{Fe}_{3} \mathrm{O}_{4} / \mathrm{Au}$ NPs could be used as seeds for continued growth of $\mathrm{Au}$ shell or Ag shell in in aqueous solution. [13] Lyon et al. provided a rapid and effective route for synthesis of magnetic core/shell particles that were soluble in aqueous media [14]. However, this method can't form Au shell on $\mathrm{Fe}_{3} \mathrm{O}_{4}$ NPs directly. The $\mathrm{Fe}_{3} \mathrm{O}_{4}$ NPs need to be exposed to air for extended periods ( $\sim 1$ week), or oxidized to form $\gamma-\mathrm{Fe}_{2} \mathrm{O}_{3}$, which decreases the saturation magnetization and elongates the synthesis time. Liu et al prepared ultra-small dimensional PVP-coated $\mathrm{Fe}_{3} \mathrm{O}_{4} / \mathrm{Au}$ nanocomposites in octyl ether by nanoemulsion polyol process [15]. However, it also needs high temperature $\left(280{ }^{\circ} \mathrm{C}\right)$ to form the $\mathrm{Fe}_{3} \mathrm{O}_{4} / \mathrm{Au}$ nanocomposites, and the transfer of the NPs from organic phase to aqueous phase. Miao et al provided a facile route at room temperature in aqueous phase [16], through 11-mercaptoundecanoic acid used as a linker, for preparation of magnetically responsive $\mathrm{Fe}_{3} \mathrm{O}_{4} @ \mathrm{Au}$. Unfortunately, this method requires tedious washing and sonicating processes as well as long preparation time (over one day). Consequently, routine synthesis often involves high temperature, several separate and time-consuming processes in order to obtain such heterostructure nanocomposites. Thus, the synthesis of a uniform and monodisperse multifunctional nanocomposite that suitably integrates $\mathrm{Fe}_{3} \mathrm{O}_{4}$ NPs and gold nanoshells, and possesses water-solubility, magnetic properties and optical stability by a rapid simple methodology at room temperature in aqueous phase is still a great challenge.

Here, we developed a simple and green method for preparing $\mathrm{Fe}_{3} \mathrm{O}_{4} @ \mathrm{Au}$ by the seed-mediated growth. The $\mathrm{Fe}_{3} \mathrm{O}_{4}$ particles were prepared by coprecipitation of an $\mathrm{Fe}(\mathrm{II})$ and $\mathrm{Fe}(\mathrm{III})$ salt in alkaline medium at room temperature. The amphiphilic, nonionic, nontoxic, polymer poly(vinylpyrrolidone) (PVP) was used as a mediator to stabilize $\mathrm{Fe}_{3} \mathrm{O}_{4}$ NPs. It provided sufficient steric stabilization for the colloids to avoid aggregation. On the other hand, it was small enough to form a relatively homogeneous and slightly negative charge layer onto $\mathrm{Fe}_{3} \mathrm{O}_{4} \mathrm{NPs}$ colloids. The number of NPs decorated with PVP could be controlled by changing the molecular weight of PVP [17]. Gold seeds $(\sim 4 \mathrm{~nm})$ with positive charge were absorbed on the PVP modified $\mathrm{Fe}_{3} \mathrm{O}_{4} \mathrm{NPs}$. Au shells were formed by reduction of $\mathrm{Au}^{3+}$ onto the surfaces of $\mathrm{Fe}_{3} \mathrm{O}_{4} \mathrm{NPs}$ by the hydroxylamine hydrochloride. To the best of our knowledge, the rapid synthesis of three-layer nanocomposites with $\mathrm{Fe}_{3} \mathrm{O}_{4}$ as the core, PVP coating as a media and $\mathrm{Au}$ shell by room temperature in aqueous solution with high yield have not been reported before. Such $\mathrm{Fe}_{3} \mathrm{O}_{4} @$ Au nanocomposites show excellent monodispersity in particle size, outstanding magnetic response, well-defined optical properties and long-term stability, which has made it promising for biomedical applications.

\section{Experiment}

\subsection{Materials}

Poly(vinylpyrrolidone) (PVP, $\mathrm{Mw}$ 58,000), ferrous chloride $\left(\mathrm{FeCl}_{2} \cdot 4 \mathrm{H}_{2} \mathrm{O}\right)$, iron(III) chloridehexahydrate $\left(\mathrm{FeCl}_{3} \cdot 6 \mathrm{H}_{2} \mathrm{O}\right)$, sodium hydroxide $(\mathrm{NaOH})$ and hydroxylamine hydrochloride $\left(\mathrm{NH}_{2} \mathrm{OH}_{3} \mathrm{HCl}\right)$ were purchased from Aladdin ${ }^{\circledR}$ (Shanghai, China). Tetrachloroauric acid $\left(\mathrm{HAuCl}_{4} \cdot 3 \mathrm{H}_{2} \mathrm{O}, 99.99 \%\right)$ and cetyltrimethyl ammonium bromide (CTAB) were purchased from Sigma-Aldrich (New Jersey, USA). Deionized water (DI, $18 \mathrm{M} \Omega \mathrm{cm}^{-1}$ ) was used in all experimental processes as needed. All materials were used as received without further processing.

\subsection{Synthesis of $\mathrm{Fe}_{3} \mathrm{O}_{4} \mathrm{NPs}$}


$\mathrm{FeCl}_{3} \cdot 6 \mathrm{H}_{2} \mathrm{O}(1.825 \mathrm{~g})$ and $\mathrm{FeCl}_{2} \cdot 4 \mathrm{H}_{2} \mathrm{O}(0.895 \mathrm{~g})$ were dissolved in $15 \mathrm{ml}$ of degased DI water. $5 \mathrm{ml}$ of $\mathrm{NaOH}$ solution $(5.8 \mathrm{M})$ was added into the iron chloride mixture dropwise by a syringe. The reaction was continues for 30 minutes with continuous stirring at room temperature under nitrogen protection. Then, washed the black precipitate with magnetic separation twice. The black $\mathrm{Fe}_{3} \mathrm{O}_{4} \mathrm{NPs}$ were re-dispersed in PVP solution with weight ratio of 1:5 to form a stable suspension.

\subsection{Synthesis of $\mathrm{Fe}_{3} \mathrm{O}_{4} @ A u$ nanocomposites}

Firstly, $4 \mathrm{~nm}$ gold seeds were prepared through borohydride reduction of gold salt in the presence of $\mathrm{CTAB}$, which also made the gold seeds positively charged. The fresh sodium borohydride solution $(0.01 \mathrm{M})$ was added to the mixture of $0.1 \mathrm{M}$ of CTAB and $0.2 \mathrm{mM}$ gold chloride acid solution. The color of the mixture turned from yellow to light brown, indicating gold seeds were formed. $2.8 \mathrm{ml}$ of diluted $\mathrm{Fe}_{3} \mathrm{O}_{4} \mathrm{NPs}$ solution $(2 \mathrm{mg} / \mathrm{ml})$ was stirred with $0.5 \mathrm{ml}$ gold seeds for 1 hours. The mixture was isolated by magnet, and the precipitates were re-dispersed in the mixture of $4 \mathrm{ml} \mathrm{DI}$ water, $0.4 \mathrm{ml}(1 \%$ wt.) citric acid and $0.2 \mathrm{ml} 0.025 \mathrm{M} \mathrm{HAuCl}_{4} \cdot 3 \mathrm{H}_{2} \mathrm{O}$. The $\mathrm{pH}$ of the mixture was adjusted to $\mathrm{pH}=9$ by $\mathrm{NaOH}$, then, $0.2 \mathrm{ml}$ of hydroxylamine hydrochloride was added. The color of the reaction solution changed from black to red wine, indicating $\mathrm{Fe}_{3} \mathrm{O}_{4} @ \mathrm{Au}$ nanocomposites were successfully synthesized.

\section{Results and discussions}

The approach for the synthesis of the $\mathrm{Fe}_{3} \mathrm{O}_{4} @ \mathrm{Au}$ nanocomposites was illustrated in scheme 1 . A "seed-mediated growth"strategy was used to synthesize the $\mathrm{Fe}_{3} \mathrm{O}_{4} @ \mathrm{Au}$ nanocomposites [18]. We chose a two-step method for preparation of $\mathrm{Fe}_{3} \mathrm{O}_{4} @ \mathrm{Au}$ nanocomposites. As shown in scheme 1, the $\mathrm{Fe}_{3} \mathrm{O}_{4}$ NPs were fabricated firstly by coprecipitating of $\mathrm{Fe}^{2+}$ and $\mathrm{Fe}^{3+}$ ions (in the molar ratio of $2: 3$ ) by alkaline solution. After 30 mins' reaction, the $\mathrm{Fe}_{3} \mathrm{O}_{4}$ NPs were precipitated by magnet, and then washed and re-dispersed in DI water. After that, the amphiphilic, nonionic, nontoxic PVP was used as a mediator to stabilize $\mathrm{Fe}_{3} \mathrm{O}_{4} \mathrm{NPs}$. It provided sufficient steric stabilization of the colloids to ensure well-dispersed magnetic particles NPs. On the other hand, it formed relatively homogeneous and slightly negative charge layer onto $\mathrm{Fe}_{3} \mathrm{O}_{4}$. Gold seeds were synthesized by borohydride reduction of gold salt in the presence of CTAB. The surfactants CTAB not only used as stabilizer for the Gold seeds, but also made the gold seeds negatively charged. The gold seeds were absorbed on the $\mathrm{Fe}_{3} \mathrm{O}_{4}$ NPs by the electrostatic interactions between the slightly negatively charged PVP on $\mathrm{Fe}_{3} \mathrm{O}_{4} \mathrm{NPs}_{\text {and }}$ positively charged gold seeds. The water-soluble core/ shell $\mathrm{Fe}_{3} \mathrm{O}_{4} / \mathrm{PVP} /$ gold seeds serve as seeds for the formation of $\mathrm{Fe}_{3} \mathrm{O}_{4} @ \mathrm{Au}$ nanocomposites with thicker Au coating. Hydroxylamine hydrochloride was used as a mild reducing agent to form thicker $\mathrm{Au}$ coating on $\mathrm{Fe}_{3} \mathrm{O}_{4}$ by simply adding more $\mathrm{HAuCl}_{4}$ in alkaline condition. The processure involved herein was perfom at room temperature and in aqueous phase. The mild and simple synthetic conditions reported here avoided the tedious procesure to transfer nanocomposites from organic phase to aqueous phase, and avoided the usage of toxic solvents.

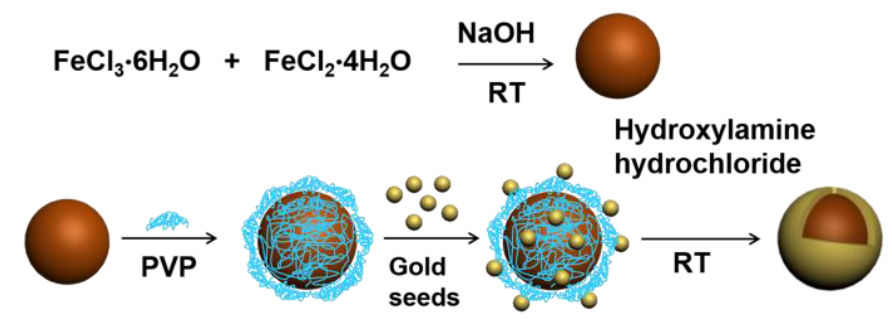

Scheme 1. Schematic synthetic route for preparation of heterostructured $\mathrm{Fe}_{3} \mathrm{O}_{4} @$ au nanocomposites at room temperature in the aqueous phase. 
We further characterized the optical and magnetic properties of synthesized magnetic nanocomposites. The product of $\mathrm{Fe}_{3} \mathrm{O}_{4} @ \mathrm{Au}$ was dispersed in aqueous solution with a well monodispersity. The nanocomposites exhibited red wine color, which indicating the formation of $\mathrm{Au}$ shell on the magnetic nanocomposites (Figure 1a). The nanocomposites were effectively separated from the solution in the presence of a magnetic field by a magnet, leaving the bulk solution clear and transparent (Fig. 1b), which demonstrated the effective magnetic separation characteristics of $\mathrm{Fe}_{3} \mathrm{O}_{4} @ \mathrm{Au}$ nanocomposites. After the removal of the external magnet and with slightly shaking, the transparent solution turned to red wine color again as shown in Figure 1a. The respective absorption spectra measured for $\mathrm{Fe}_{3} \mathrm{O}_{4} \mathrm{NPs}$, Au seeds and $\mathrm{Fe}_{3} \mathrm{O}_{4} @ \mathrm{Au}$ were shown in Figure 2. The solution of $\mathrm{Fe}_{3} \mathrm{O}_{4}$ NPs and $\mathrm{Au}$ seeds did not show any obvious measurable surface plasmon resonance (SPR) peak in the visible region. However, the $\mathrm{Fe}_{3} \mathrm{O}_{4} @$ AuNPs showed a clear SPR peak at $540 \mathrm{~nm}$, indicating the formation of $\mathrm{Au}$ shell on $\mathrm{Fe}_{3} \mathrm{O}_{4}$ NPs. Measurements of the SPR band of the NPs provided complementary evidence of the $\mathrm{Fe}_{3} \mathrm{O}_{4} @$ Au nanocomposites.
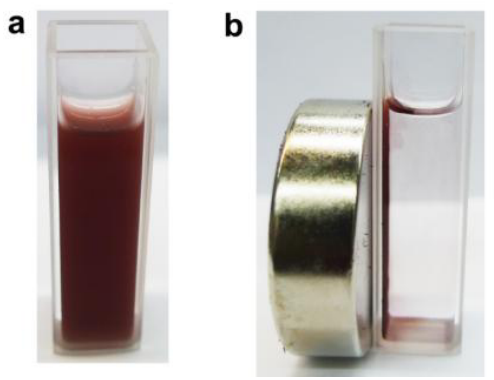

Figure 1. Photo images of $\mathrm{Fe}_{3} \mathrm{O}_{4} @$ Au with absence (a) and presence (b) of an external magnet.

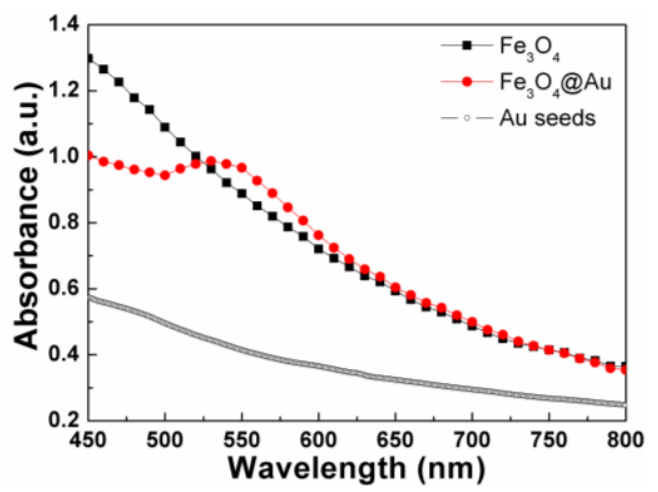

Figure 2. Absorption spectra for $\mathrm{Fe}_{3} \mathrm{O}_{4} \mathrm{NPs}$, Au seeds and $\mathrm{Fe}_{3} \mathrm{O}_{4} @ \mathrm{Au}$ nanocomposites.

In order to further determine the crystallinity and structure of the nanocomposites, powder X-ray diffraction (XRD) spectrum was utilized. Figure 3 showed the XRD of $\mathrm{Fe}_{3} \mathrm{O}_{4} @ \mathrm{Au}$ and the corresponding standard cards, JCPDS 88-0315 for $\mathrm{Fe}_{3} \mathrm{O}_{4}$ and 04-0784 for cubic gold. The line broadening observed in the XRD spectra is indicative of the small size of the NPs. All the patterns of the $\mathrm{Fe}_{3} \mathrm{O}_{4} @ \mathrm{Au}$ nanocomposites are in agreement with the spectral peak of gold standard XRD diffraction spectrum (JCPDS \# 4-0784), as well as the standard of $\mathrm{Fe}_{3} \mathrm{O}_{4}$ diffraction spectrum (JCPDS \# 88-0315). XRD patterns for $\mathrm{Fe}_{3} \mathrm{O}_{4} @ \mathrm{Au}$ NPs show characteristic peaks (at $2 \theta=30.157^{\circ}, 35.521^{\circ}$, $43.172^{\circ}, 53.561^{\circ}, 57.098^{\circ}, 62.703^{\circ}$ ), are in corresponding with their indices (220), (311), (400), (422), (511) and (440) of $\mathrm{Fe}_{3} \mathrm{O}_{4}$ with cubic phase (JCPDS 88-0315), indicating that the NPs are pure $\mathrm{Fe}_{3} \mathrm{O}_{4}$. Besides the XRD patterns belonging to $\mathrm{Fe}_{3} \mathrm{O}_{4}$ (JCPDS 88-0315), all the other diffraction peaks at $2 \theta=38.184^{\circ}, 44.392^{\circ}, 64.576^{\circ}$, and $77.547^{\circ}$, are identified as characteristic (111), (200),(220) and (311) planes of cubic Au (JCPDS 04-0784). 


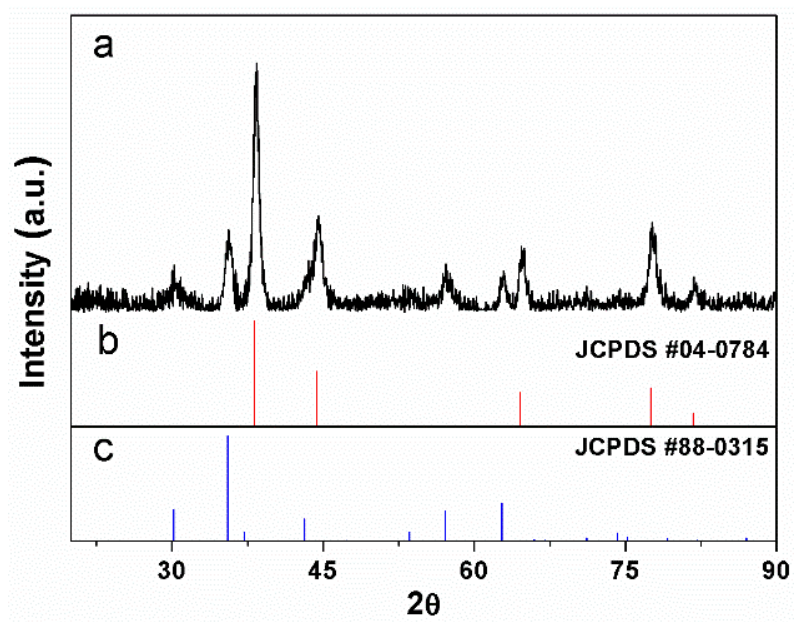

Figure 3. (a) XRD diffraction patterns of the as-prepared $\mathrm{Fe}_{3} \mathrm{O}_{4} @ \mathrm{Au}$, and the corresponding standard XRD diffraction spectrum (b) $\mathrm{Au}$ (JCPDS \#04-0784) and (c) $\mathrm{Fe}_{3} \mathrm{O}_{4}$ (JCPDS \#88-0315)

The magnetic properties of as-synthesized $\mathrm{Fe}_{3} \mathrm{O}_{4}$ and $\mathrm{Fe}_{3} \mathrm{O}_{4} @$ Au nanocomposites were measured by vibrating sample magnetometer at room temperature $(300 \mathrm{~K})$. The field-dependent magnetization curves shown in Figure 4 demonstrated that $\mathrm{Fe}_{3} \mathrm{O}_{4}$ and $\mathrm{Fe}_{3} \mathrm{O}_{4} @ \mathrm{Au}$ nanocomposites were superparamagnetic with a saturation magnetization values of 60 and $40 \mathrm{emu} / \mathrm{g}$, respectively. A slight decline of the saturation magnetization value of $\mathrm{Fe}_{3} \mathrm{O}_{4} @ \mathrm{Au}$ after coating $\mathrm{Au}$ was due to the diamagnetic contribution of the $\mathrm{Au}$. Fortunately, the saturation magnetization value of $\mathrm{Fe}_{3} \mathrm{O}_{4} @ \mathrm{Au}$ was relatively high compared with the literature reported previously [16]. The maximum magnetization value of the core/shell magnetic NPs was around 10-20 emu/g at room temperature [19]. The direct coating of $\mathrm{Au}$ onto magnetic NPs severely decreased the saturation magnetizationof the magnetic core by $78 \%$ or more.[20,21]. In our method, PVP as a coupling agent, not noly prevented the magnetic NPs form large-sized aggregated precipitates in solutions, but also decreased the effect of Au coating on the magnetic properties of $\mathrm{Fe}_{3} \mathrm{O}_{4} @ \mathrm{Au}$ nanocomposites. As a result, the PVP-processed $\mathrm{Fe}_{3} \mathrm{O}_{4} @ \mathrm{Au}$ nanocomposites with high saturation magnetisation improved the performance of operation and offer potential applications in different areas.

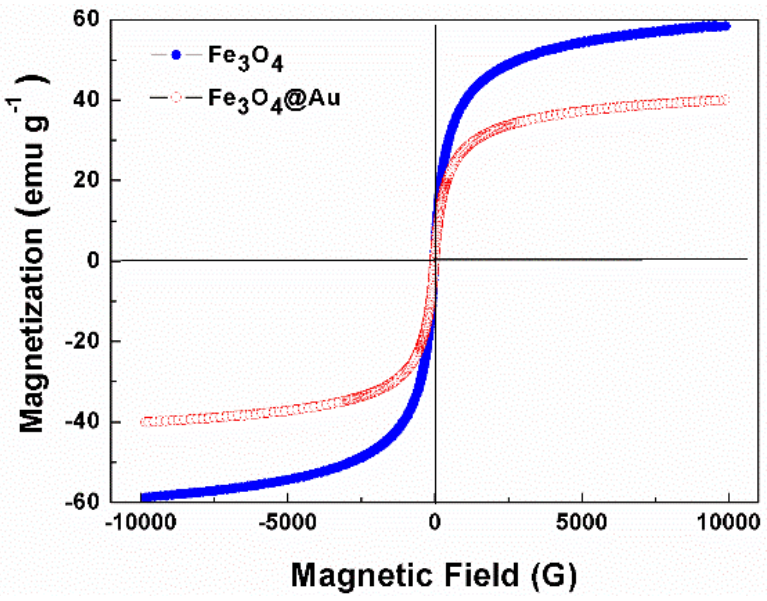

Figure 4. Hysteresis loops of (a) $\mathrm{Fe}_{3} \mathrm{O}_{4}$, (b) $\mathrm{Fe}_{3} \mathrm{O}_{4} @ \mathrm{Au}(300 \mathrm{~K})$ 


\section{Conclusions}

In this research, we proposed a simple, rapid, non-toxic method for synthesis of water-soluble $\mathrm{Fe}_{3} \mathrm{O}_{4}$ ( $\mathrm{Au}$ nanocomposites in aqueous solution at room temperature. The synthesized multifunctional super-paramagnetic nanocomposites displayed interesting plasmonic properties and high saturation magnetization, which could be applied for various bio-applications. The significant contributions of the synthesis are listed as flowing. It offers a simple, fast and green method for preparing of multifunctional magnetic nanocomposites at room temperature in aqueous solution with large scale. It avoids tedious procedures to transfer the magnetic nanocomposites form organic phase to aqueous phase, and avoid the usage of toxic reagents (e.g. benzene). We anticipate that such multifunctional magnetic nanocomposites will have great potentials for nanoparticle-based diagnostic and therapeutic applications due to its magnetization and optical properties.

\section{Acknowledgments}

The authors acknowledge the financial support from the Natural Science Foundation of China $(81501556,61672146,51502034)$ and the Fundamental Research Funds for the Central Universities (141903001).

\section{References}

1. C. Wen, L. Wu, Z. Zhang, Y. Liu, S. Wei, J. Hu, M. Tang, E. Sun, Y. Gong, J. Yu, D. Pang, Acs Nano 8, 941 (2014).

2. J. Bao, W. Chen, T. Liu, Y. Zhu, P. Jin, L. Wang, J. Liu, Y. Wei, Y. Li, Acs Nano 1, 293 (2007).

3. M. Liong, A. N. Hoang, J. Chung, N. Gural, C. B. Ford, C. Min, R. R. Shah, R. Ahmad, M. Fernandez-Suarez, S. M. Fortune, M. Toner, H. Lee, R. Weissleder, Nat. Commun. 4, 1752 (2013).

4. Y. Pan, X. Du, F. Zhao, B. Xu, Chem. Soc. Rev. 41, 2912 (2012).

5. Y. Yuan, Z. Ding, J. Qian, J. Zhang, J. Xu, X. Dong, T. Han, S. Ge, Y. Luo, Y. Wang, K. Zhong, G. Liang, Nano Lett. 16, 2686 (2016).

6. K. M. Mayer, J. H. Hafner, Chem. Rev. 111, 3828 (2011).

7. K. Saha, S. S. Agasti, C. Kim, X. Li, V. M. Rotello, Chem. Rev. 112, 2739 (2012).

8. L. Dykman, N. Khlebtsov, Chem. Soc. Rev. 41, 2256 (2012).

9. Y. Jin, C. Jia, S. Huang, M. O'Donnell, X. Gao, Nat. Commun. 1, 41 (2010).

10. Q. Wei, H. Song, A. P. Leonov, J. A. Hale, D. Oh, Q. K. Ong, K. Ritchie, A. Wei, J. Am. Chem. Soc. 131, 9728 (2009).

11. WangWang, J. Luo, Q. Fan, M. Suzuki, I. S. Suzuki, M. H. Engelhard, Y. Lin, N. Kim, J. Q. Wang, C. Zhong, J. Phys. Chem. B 109, 21593 (2005).

12. H. Park, M. J. Schadt, Wang, I. S. Lim, P. N. Njoki, S. H. Kim, M. Jang, J. Luo, C. Zhong, Langmuir 23, 9050 (2007).

13. Z. Xu, Y. Hou, S. Sun, J. Am. Chem. Soc. 129, 8698 (2007).

14. J. L. Lyon, D. A. Fleming, M. B. Stone, P. Schiffer, M. E. Williams, Nano Lett. 4, 719 (2004).

15. H. Liu, P. Hou, W. Zhang, J. Wu, Coll Surf A: Phys Eng Asp 356, 21 (2010).

16. X. Miao, T. Wang, F. Chai, X. Zhang, C. Wang, W. Sun, Nanoscale 3, 1189 (2011).

17. J. Cha, P. Cui, J. Lee, J. Mater. Chem. 20, 5533 (2010).

18. K. Yong, Y. Sahoo, M. T. Swihart, P. N. Prasad, Coll Surf A: Phys Eng Asp 290, 89 (2006).

19. C. Wu, Y. Huang, P. Chen, K. Hoshino, H. Liu, E. P. Frenkel, J. X. J. Zhang, K. V. Sokolov, Acs Nano 7, 8816 (2013).

20. I. Chiang, D. H. Chen, Adv. Funct. Mater. 17, 1311 (2007).

21. L. Wang, H. Park, S. I. Lim, M. J. Schadt, D. Mott, J. Luo, X. Wang, C. Zhong, J. Mater. Chem. 18, 2629 (2008). 